\title{
Features of Vocabulary of Preschool Children with Speech Disorders
}

\author{
Akhmedova Oydin Sadriddinovna \\ Tashkent State Pedagogical University 13.00.03-1st stage doctoral student on \\ specialty of special pedagogy \\ sadriddinovnaoydin@gmail.com \\ $+(998) 97-447-16-07$
}

Resume: In this article, the author refers to studies devoted to the ontogeny of vocabulary development in preschool children. The article reveals the importance of vocabulary in the full development of speech in preschool age. The main value of the article is empirical research to identify the characteristics of vocabulary in preschoolers with speech impairments.

Key words: vocabulary, cognitive processes, speech, preschool age, paraphasia, thinking, presentation.

Speech is a specific form of communication, inherent only in people to influence each other. According to EF Arkhipova, a word is a nominative unit of language that serves as the name of an object, its attribute and action. As DE Rosenthal informs us, not a single word in our language exists separately from the nominative system; they are also combined into certain groups based on various characteristics. One and the same, it can be assigned to several semantic categories. NM Shansky describes the word as an impenetrable, non-two-hitting unit of language that has a constancy of sound and meaning. If the stock of words in the memory and everyday life of a person is small, then speech is simply impossible. Our life cannot be imagined without communication, in which verbal communication takes the leading role. We master our native language in order to become a person, to have our own position in life, to enter into relationships, to try on different social roles. It is more pleasant and interesting to communicate with a person who can operate with a sufficiently large number of words that differ in their meaning. Therefore, for the development of correct, high-quality and understandable speech, it is important that the dictionary is full and varied.

Language is the communication that people use to communicate with their interlocutors about certain situations in the world, to convey messages about their ideas, feelings, experiences, intentions, goals, and the results of cognitive activities. is one of the most diverse character systems you use to share information.

Today, one of the topical topics in a child's speech development is the state of his vocabulary. One can notice such a tendency that the vocabulary of children is insufficiently developed, in expressive speech they are limited to a small number of words, rarely use adjectives and therefore can hardly clearly express their feelings and thoughts.

Vocabulary is the best option speech activity in the process of solving problems of speech communication. Insufficiently developed speech activity negatively affects all areas the personality of the child: the development of his cognitive activity is hampered, the productivity of memorization decreases, the logical and semantic memory, children hardly master mental operations, are disturbed all forms of communication and interpersonal interaction, essentially the development of play activity is inhibited, which, as in the norm, leading importance in terms of general mental development.

Numerous researchers and scholars have dealt with the problem of vocabulary development. Thus, A. V. Zaporozhets, D. B. Elkonin note that the conditions of life and

ISSN: 0010-8189

(C) CONVERTER 2021

www.converter-magazine.info 
upbringing have a great influence on the state of the child's vocabulary. A.N. Gvozdev in his works emphasizes that the main base of the child's vocabulary is formed during the middle preschool age, and subsequently it is actively supplemented. Also A. N. Leont'ev found that by the end of the preschool period of the child's development, the vocabulary is already quite extensive, but not yet refined enough. Children still misunderstand and use words.

Such famous scientists as R. E. Levina, T. B. Filicheva, G. V. Chirkina, R. I. Lalaeva studied the development of vocabulary in children with speech disorders. They made a great scientific contribution to speech therapy, describing how vocabulary develops in various speech disorders, and also developed various methods for studying vocabulary and working to overcome vocabulary development disorders in preschool children.

The problem of the scanty vocabulary of adjectives in children with general speech underdevelopment is urgent now. A.V. Davydova, who studied the state of the adjective vocabulary in children with various speech disorders and came to the conclusion that the subjects often do not know how to designate the relationship of belonging with the help of an adjective, instead they use the genitive case of the specified noun, which indicates two things - a narrow vocabulary and inability to form possessive adjectives.

A significant part of the modern child population is characterized by the presence of various disorders of speech development. The most gross violations of the speech system and the communicative sphere of children are noted with a general underdevelopment of speech.Scientists N.S. Zhukova, R.I. Lalaeva, N.V. Serebryakova, T.B. Filicheva, G.V. Chirkina and others noted and characterized the originality of the mastery of the lexical system by children with general speech underdevelopment. In children with general speech underdevelopment, vocabulary is formed at a slower pace, while at the same time, they have an unformed process of inflection and word formation, semantic and formal-linguistic components of vocabulary. The manifestations of violations of the formation of the lexical system of speech are diverse and require careful study.

The vocabulary of a language is an indicator of a high level of speech development and a necessary condition for the development of communicative skills and abilities. A preschooler should be able to communicate with peers and adults, read successfully in school, and master words that allow them to understand their literary works.

Examples of mastering the lexical structure of speech in the ontogenesis of speech activity V.I. Beltyukova, A.N. Gvozdeva, S.N. Zeitlin, O.S. The works of Ushakova and other scholars describe the formation of children's speech from childhood and show that speech is the most important component of all neuropsychological development.

There are many studies in the literature on lexical side of speech and its correction in preschoolers with speech disorders (R. I. Lalaeva, R. E. Levina, L. V. Lopatina, N. V. Serebryakova, T. B. Filicheva, G. V. Chirkina and others). They discovered and identified lexical violations that have specificity, these include features such as an unsatisfactory level of development vocabulary, a significant difference when correlating the volume of active and passive vocabulary, the use of words that do not correspond to speech situations, numerous verbal paraphasias, unformed semantic fields, as well as obstacles when trying to update dictionary.

The development of speech activity goes hand in hand with the development of other higher mental functions, which in turn stimulates the knowledge of the world. All this is connected with the senses, because through them we receive information about the world around us. Communication with adults and peers plays a very significant role in a child's speech development. Because speech cannot develop on its own, without an example from outside. Initially, the child tries to imitate the sounds that he hears every day from loved ones, then he

ISSN: 0010-8189

(C) CONVERTER 2021

www.converter-magazine.info 
learns to correctly put sounds into syllables, syllables into words, and words into sentences. And together with the phonetic-phonemic side of speech, its lexical-grammatical structure also develops. The formation of vocabulary in children begins at eleven to twelve months of life. It is known that the initial vocabulary of children in this period is still very small (8-10 words), but in the later years it increases sharply. One of the main reasons for the increase in vocabulary of the child during this period of life, in our opinion, is the mastery of the function of walking upright. As a result of walking, the baby's field of vision expands significantly, as the field of vision increases, in which case more objects and events begin to be perceived by the child than before.

A toddler's primary vocabulary from the age of one to two usually consists of names of things and actions that are used on a daily basis, have a clear meaning, and are not generalized or abstract. In addition to correctly pronounced words, the child uses expressive-mimic tools, gestures, imitation of sounds (bux, af-af, kss, taq-taq, no, etc.), which is for this age is the linguistic norm. They all refer to objects, actions, and objects that can be freely used in manipulation, mastering game plots, and interacting with others.

The active vocabulary of a three-year-old gradually grows to 300-400 words. Qualitative analysis of the dictionary shows that the number of grammatical and paralinguistic means of communication is significantly reduced and they are replaced by correctly pronounced words. A.N. Gvozdeva, A.V. In Zakharova's work, the most common words in young children's speech are horses and verbs, and adjectives and pronouns are difficult to master and rarely used. ${ }^{1}$

Practice shows that mastering words with abstract meanings (news, joy, politeness) requires purposeful pedagogical training, because at the age of three the child still has difficulty in identifying words with an abstract component. It is almost impossible for a child to learn meaning based on a comparison of the options for using them in the context of speech, because during this period he has a visual-subjective thinking.

When a 3-4-year-old child is already fully mastering the subject-practical activity and actively mastering the plot game, his vocabulary expands to two to three thousand words. Some of them already have a generalizing and figurative meaning, which is explained by the active formation of new, visual-figurative thinking.

The sound shell of words is getting closer to the norm of pronunciation: the number of omissions, additions and substitutions of sounds and syllables decreases; the formation of new units is actively manifested by the similarity to the options used. However, in addition to the passive vocabulary, there are about a few hundred words that the child understands well but does not use in speech.

The active vocabulary of children between the ages of 5 and 7 is very rich and diverse, constantly expanding and improving with the help of adults. With the development of mental processes (word-logical thinking, perception, imagination, memory), the expansion of connections with the outside world, the enrichment of the child's emotional experience, the qualitative change in activity, vocabulary also improves quantitatively and qualitatively.

The learning of new words by an older preschooler develops so rapidly that the process cannot be fully understood. The dictionary of a child entering school contains from three to seven thousand, and in some cases up to ten thousand words, which are dominated by abstract nouns, verbs, and adjectives.

During this period, the process of formation of phonetic-phonemic processes is completed, which is qualitatively reflected in the vocabulary of children. Children's speech is already accurate and understandable, takes the form of "adult" communication, and truly becomes a means of communication and information. This can be done provided that there are no deviations

\footnotetext{
${ }^{1}$ Гвоздев, А.Н. Вопросы изучения детской речи. - СПб: Детство-Пресс, 2007. - 480 с. ISSN: 0010-8189

(C) CONVERTER 2021

www.converter-magazine.info
} 
in the child's speech apparatus, mental development, as well as in the upbringing of the child in a normal speech social environment.

So, the development of the child's vocabulary occurs gradually in the process of communicating with the people around and learning about the world. Vocabulary enrichment plays a large role in a child's cognitive development. During the development of vocabulary, the word changes its meaning and becomes overgrown with connections with other words. All this is presented in the form of semantic fields. With words, the child expresses what he is able to understand. Consequently, the more extensive and the development of the active and passive vocabulary, the more the child can understand and, most importantly, convey his thoughts and feelings to the people around him.

This means that during the school education phase, all the speech skills and abilities of the previously formed children will be improved and written speech will gradually become a means of acquiring and expressing students 'knowledge.

Thus, we have shown that the process of formation of vocabulary in the preschool period is a complex, multi-stage phenomenon in the development of each person.

One of the most interesting features of preschool speech ontogenesis is the errors in speech, under which S.N. Citlin "understands any cases of deviation from the norms of the current language" ${ }^{2}$. According to the scientist, their emergence is due to the peculiarities of both the language system of the mother tongue itself and the ontogenesis of speech.

Practice shows that the number of lexical errors in children with normal speech development is small, and in children with speech defects is several times higher. A distinctive feature of the vocabulary of children in this category is the significant individual differences, which are mainly due to the pathogenesis of speech development.

Research in the field of speech therapy for children reveals lexical deficiencies resulting from various combinations of biological and social causes in children with alalia, dysarthria, and incomplete speech development (NTR). In most cases, the pathological mechanism of lexical and grammatical development is V.A. Kovshikov found that the child's ability to program speech was caused by factors such as the lack of linguistic operations for the production of words. ${ }^{3}$.

Lexical errors in speech-impaired children are usually due to limited vocabulary, difficulties in developing it, as well as the lack of formation of semantic fields in R.I. Lalaeva, N.V. Studied by Serebryakovas ${ }^{4}$.

The typology of errors has certain individual characteristics depending on the nature of the speech disorder specific to a particular child and is manifested in the following options:

- Verbal paraphases (substitutions) of words in the same lexical group (close in meaning) and in different semantic areas;

- Difficulties in updating the dictionary;

- misuse of antonyms, words with abstract and generalizing meanings;

- as well as when using ambiguous words.

One of the distinctive features of the vocabulary of children with speech defects is the presence of verbal paraphases. Practice shows that it is often common to replace words belonging to the same semantic group. Preschoolers can use words in an overly broad sense (the generalized concept of shoes is used instead of the word shoe), and sometimes, conversely, in a

\footnotetext{
${ }^{2}$ Ковшиков, В.А. Экспрессивная алалия. - М.: Институт общегуманитарных исследований, В. Секачев, 2001. $96 \mathrm{c}$.

${ }^{3}$ Ковшиков, В.А. Экспрессивная алалия. - М.: Институт общегуманитарных исследований, В. Секачев, 2001. $96 \mathrm{c.}$

${ }^{4}$ Лалаева, Р.И., Серебрякова, Н.В. Коррекция общего недоразвития речи у дошкольников (формирование лексики и грамматического строя). - СПб.: Союз, 1999. - 160 с.
}

ISSN: 0010-8189

(C) CONVERTER 2021

www.converter-magazine.info 
very narrow sense (children with the generalized concept of birds, sparrows) called). Often this word is used only in a particular case and is not used to describe other situations.

An empirical study of the typology of lexical errors in children's speech was conducted on the basis of special preschool educational institutions No. 480, 511 in Yunusabad district of Tashkent. The following principles form the basis of speech therapy examination techniques in the study of vocabulary in children with speech defects. Their use is determined by ontogenetic laws in the development of children's speech and cognitive activity.

1. The thematic principle of vocabulary selection is usually the main one in the development of a child speech study statement. This principle stipulates that the lexical material under study should be grouped according to specific thematic cycles, which traditionally include "Toys", "Body Parts", "Fruits", "Vegetables" and others. Such a distribution allows the expert to identify speech impediments associated with limited ideas about the world around them.

2. It is known that in the process of compiling lexical material, experts always take into account the age-related features of children's speech: the older the subject, the more units the lexical program of speech therapy should include. In this regard, it is important to emphasize the adherence to the ontogenetic principle. For example, when studying the vocabulary of 2-3 year olds, we should be limited to a very narrow vocabulary that should include "Family", "Body Parts". "Toys", "Pets and Birds", as well as "Nearby Objects" - this cycle can be divided into narrower groups: "Furniture", "Foods", "Clothes" for older preschoolers. And, conversely, the diagnostic program should include cycles on "Trees," "Shrubs," "Hats," "Educational Materials," and "Animals of Tropical Countries," to check the speech of small preschoolers.

3. The communicative principle, according to which the lexical program should include the following:

- The most common words in the native language,

- words with alternative sound-syllable structure appropriate for children's age.

4. The semantic principle includes parts of objects (chair: chair, legs), signs of objects (high, wooden, hot) and verbs (crawling, jumping) in the examination program. it also means the inclusion of words denoting qualitative properties (bright, solid) and the spatial-temporal relationship (long, distant) between an object and an event.

5. According to the lexical and grammatical principle, speech therapy should include different word groups: not only nouns, verbs and adjectives, but also rhymes, adverbs.

Using these principles, we believe, will help us create a qualified speech therapy examination program for each speech therapist. In the future, such a lexical program will help to identify the main sections and content of vocabulary work, as well as determine the minimum level that children should master.

Experimental study of the typology of lexical errors in children's speech was conducted by us from October 2020 to April 2021 in 4 special preschool educational institutions No. 480, 511 in Yunusabad district of Tashkent. The experimental group consisted of 36 pre-school children aged 6 to 7 years with speech therapy findings such as "dysarthria", "alalia".

The study of children's speech was carried out using the following traditional speech therapy methods, which are covered in special scientific and methodological literature:

- Conversation with the child,

- narration of a literary text,

- create a story based on a picture or a series of pictures,

- Repetition of words and sentences after adults: "Get me back",

- talk about pictures with a plot or theme,

ISSN: 0010-8189

(C) CONVERTER 2021

www.converter-magazine.info 
- Speech and didactic games: "Complete the sentence", "Say the opposite", "Say it differently3", "Who is this (what)?", "Continue the line of objects", "Name the picture", "A word name it "," What did the cook cook? "," Who is doing what? " and others.

An analysis of the research materials showed that the most common lexical errors in speech in children with speech defects are:

1. Misuse of verbal paraphrases and phrases (nouns, verbs and adjectives). Changes can be temporary, accidental, and at the same time related to a particular situation (interference) or permanent. Typically, substitutions are represented by a single word, less often - by a phrase or sentence. The following substitutions are distinguished between horses:

- Concepts specific to one lexical group: lion - tiger, deer - deer, coat - shirt, sweater - Tshirt, skirt - shirt;

- generalize words as a specific concept and vice versa: shoes - shoes, ethics; clothes sweaters, clothes; transport - cars; dovdirak - a bird;

- words denoting objects and their parts: pipe - stove, window sill, train - wagon;

- words denoting parts of the body of humans and animals: beard - beak, shoulder - elbow;

- words denoting the profession of people: instead of a driver - a machinist or driving a car; instead of a cook - cooks;

- words expressed by a different set of words from the same semantic field: instead of an iron - hot, instead of wild animals - ruthless, instead of a ruler - measuring.

The following substitutions are characteristic for verbs: actions that are similar in terms of situation and meaning, similar to words in the same semantic field: instead of knocking down a redwood tree - hit a redwood tree; instead of boiling, frying, steaming - cooking; bathing washing.

- actions with words in other semantic areas: instead of the sun shining - the sun loves the morning; redness knocks on the tree - the bird heals the tree;

- actions expressed in a phrase or sentence3: instead of my mother making soup - my mother prepares food; instead of my mother frying fish - my mother makes fish.

Disadvantages of using adjectives:

- words denoting the size of items: long, tall, instead of wide - large; instead of short, low, narrow, thick - small;

- Signs of things that express taste, color, etc .: sweet - tasty, bitter - bad, unpleasant;

2. Deficiencies in word actualization are associated with limited general perceptions and speech experience. These include:

- In the shortcomings of the phonetic structure of the word: instead of a bicycle - a bicycle;

- In the choice of words denoting natural phenomena (storm, thunder, storm), the names of objects: tools (saw, hammer), hats (panama, beret), birds (sparrow, goose), animals (giraffes, tigers), insects (ants, dragonflies) and others.

Difficulties in using abstract, polysemantic, and complex words can be explained by the specificity of children's thinking, limited knowledge and perceptions of the environment, as well as a lack of linguistic ability. Children cannot say the words happiness, friendship, news and do not understand the meaning.

Research has shown that all children, regardless of age, have difficulty understanding the meaning of the words street, monument, flowerbed, landscape, theater.

The discrepancy in the volume of passive and active vocabulary is a rather characteristic feature of the speech of children with general speech underdevelopment: they understand the meanings of many words, and the volume of their passive vocabulary is close to the norm, but nevertheless the use and actualization of words in independent speech causes great difficulties. Misunderstanding of the meanings of individual speech units leads to their peculiar use, to

ISSN: 0010-8189

(C) CONVERTER 2021

www.converter-magazine.info 
frequent replacement of one name with another. Substitutions occur both in terms of semantic and sound and morphological characteristics.

For preschoolers and elementary school students, the predominant use of nouns with a specific, everyday meaning and verbs denoting the everyday, well-known actions of people around and their own actions is characteristic. Thus, with a fairly large stock of words denoting objects and actions, their operation turns out to be not always accurate.So, lexical errors appear when using nouns with abstract, abstract and generalized meaning (friendship, health, furniture, transport), as well as less common words denoting the names of parts of the body of people and animals (elbows, shoulders, mane, comb), parts of objects (seat, bottom, shelf), tools (saw, hammer), professions (driver, builder, writer), trees and flowers (pine, birch, chamomile, cornflower), fruits and vegetables (plum, peach, radish, beet), animals and birds (elk, giraffe, crane, woodpecker, chicken).

Adjectives are used by children with speech disorders somewhat less often and denote mainly the color, shape, size and some other qualities of objects. Adjectives denoting material (woolen, leather), character traits (sad, brave, happy), temporal and spatial signs of objects (deep, slow, autumn, night) are used much less often. Apparently, the substitutions of adjectives are carried out due to the inability to differentiate signs size, height, thickness, width (high - long, low - small, narrow - thin, short - small).

The study showed that the state of children's vocabulary reflects the nature of their immediate environment and upbringing, as well as the intrafamily speech microenvironment. So, children from pedagogically neglected and socially disadvantaged families, where non-working grandmothers and great-grandmothers are engaged in upbringing, and parents abuse alcohol, more often use dialecticisms and vernaculars (vavka - wound, shishak - bump, babulence grandmother, beet - beets, kutyats - puppies), as well as onomatopoeic words and gestures (ticktock, melon-melon - ticking, thunderstorm dzh-w - thunders, bibika - machine). The aforementioned lexical shortcomings are also characteristic of children brought up in conditions of overprotection, "lisping" and excessive familiarity.

The study revealed that children with speech underdevelopment experience difficulties in using some adverbs (inside, on time, thickly), possessive (fox, wolf) and relative (woolen, leather) adjectives, do not use short adjectives at all (bel, red, evil), and the superlative degree of adjectives is used in combination with the word very. When choosing antonyms, a fairly common way is to use the particle not (stupid, not good).

Thus, a study of the oral speech of children with speech impairments showed that they were characterized by lexical errors due to limited vocabulary, poor perceptions of the world around them, and deficiencies in cognitive development. Difficulties in choosing the right words are explained by shortcomings in thinking processes and underdeveloped operations of analysis, comparison and generalization.

Inconsistency of passive and active vocabulary Speech is a characteristic feature of speech of children who are not fully developed: they understand the meaning of many words and their passive vocabulary is close to the norm, but still the use is independent. Actualizing words in a conversation poses great challenges.

Given that the majority of preschool children develop speech late and appear at about age three, their speech experience is very small and limited. Thus, these facts have a significant impact on the formation of children's speech and vocabulary development.

Children's speech; The principles we have presented (thematic, ontogenetic, communicative, semantic, lexical-grammatical and methodological) for the selection and construction of lexical material in the study, in our opinion, assessing the nature, extent, and causes of possible disorders, as well as identifying key areas of speech therapy.

ISSN: 0010-8189

(C) CONVERTER 2021

www.converter-magazine.info 


\section{References:}

1. Гвоздев, А.Н. Вопросы изучения детской речи. - СПб: Детство-Пресс, 2007. - 480 с.33

2. Ковшиков, В.А. Экспрессивная алалия. - М.: Институт общегуманитарных исследований, В. Секачев, 2001. - 96 с.3

3. Лалаева, Р.И., Серебрякова, Н.В. Коррекция общего недоразвития речи у дошкольников (формирование лексики и грамматического строя). - СПб.: Союз, 1999. - 160 с.

ISSN: 0010-8189 